\title{
HALL EFFECT STUDIES OF THE SUPERCONDUCTING FERROMAGNET UCoGe
}

\author{
Danica Krstovska $^{1 *}$, Eden Steven ${ }^{2}$, Andhika Kiswandhi ${ }^{2}$, James S. Brooks ${ }^{2}$ \\ ${ }^{1}$ Institute of Physics, Faculty of Natural Sciences and Mathematics, Ss. Cyril and Methodius University, \\ Skopje, Republic of Macedonia \\ ${ }^{2}$ National High Magnetic Field Laboratory, Florida State University, \\ Tallahassee, FL 32310, U.S.A.
}

*Corresponding author, e-mail: danica@pmf.ukim.mk

\begin{abstract}
We find that the Hall effect in a single crystal of UCoGe varies as a function of the angle $\theta$ between the applied magnetic field and the easy magnetic axis up to fields of $18 \mathrm{~T}$ at $0.2 \mathrm{~K}$, i.e. in the region where both superconductivity and ferromagnetic order coexist. Instead of following the conventional $\cos \theta$ dependence the two components that comprise the total Hall resistance, the anomalous and ordinary Hall effect, exhibit quite an unusual behavior with the field direction. The anomalous Hall effect is found to be determined by the parallel component of the magnetization. We suggest that the field induced changes in magnetization due to the field rotation play an important role in the observed unusual behavior. The ordinary Hall effect cannot be described by the simple relation to the perpendicular component of the magnetic field implying that this component of the Hall effect may be also affected by the variations in magnetization at the characteristic field (kink field). A field induced moment polarization is also observed in Hall effect as in magnetoresistance, which advances previous findings in UCoGe. The Hall effect slope reverses sign at the kink field indicative of small but possible Fermi surface reconstruction around this field. Our findings show that in UCoGe multiple mechanisms contribute to the observed field induced moment polarization at the kink field.
\end{abstract}

Key words: superconductivity; ferromagnetism; uranium compound; UCoGe; anomalous Hall effect; ordinary Hall effect; kink field; field induced moment polarization; Fermi surface

\section{INTRODUCTION}

The discovery of superconductivity coexisting with ferromagnetism in three uranium based compounds $\mathrm{UGe}_{2}$ (under pressure) [1], URhGe [2] and most recently UCoGe [3] has attracted much interest due to the unusual properties of the superconducting state. In these materials superconductivity develops below the ferromagnetic Curie temperature $\left(\mathrm{T}_{\text {Curie }}\right)$ without destroying magnetic order. The $5 f$ electrons of uranium atoms have a strong itinerant character, and are believed to contribute to both superconductivity and magnetism. Among the ferromagnetic (FM) superconductors discovered so far, UCoGe is one of the most readily explored experimentally, because of its high superconducting (SC) transition temperature $\left(\mathrm{T}_{\mathrm{SC}}\right)$ and low Curie temperature $\left(\mathrm{T}_{\text {Curie }}\right)$ at ambient pressure [3]. Microscopic measurements have shown that supercon- ductivity occurs within the FM region, resulting in microscopic coexistence of ferromagnetism and superconductivity $[4,5]$. Studies of the SC upper critical field $\left(\mathrm{H}_{c 2}\right)$ and its angle dependence along each crystalline axis have reported remarkable enigmatic behavior $[6,7]$ : superconductivity survives far beyond the Pauli-limiting field along the $a$ and $b$ axes, whereas $\mathrm{H}_{c 2}$ for fields along the $c$ direction $\left(\mathrm{H}_{c 2}^{c}\right)$ is as small as $0.5 \mathrm{~T}$. Colossal $\mathrm{H}_{c 2}$ for fields along the $a$ and $b$ axes seems to suggest spin triplet pairing. In addition, a steep angle dependence of $\mathrm{H}_{c 2}$ was reported when the field was tilted slightly from the $a$ axis toward the $c$ axis [7]. The observed characteristic $\mathrm{H}_{c 2}$ behavior is one of the mysterious features of SC in UCoGe and its origin can be related to the mechanism of the superconductivity.

Shubnikov de Haas oscillations (quantum oscillations of the resistance with magnetic field) and thermopower measurements of $\mathrm{UCoGe}$ revealed a 
topological change in the Fermi surface of UCoGe $[8,9]$. A small pocket Fermi surface exists with large cyclotron mass implying a low carrier density system with a heavy electronic state realized in UCoGe. Also, the thermoelectricity measurements show that under magnetic field applied along the $b$ axis (perpendicular to the easy axis), a sharp peak is observed in the thermopower of UCoGe at $B=11.1$ $\mathrm{T}$ and low temperature $T=0.35 \mathrm{~K}$ and at higher field, the thermopower changes sign which suggests a modification of the Fermi surface. It is very important to know if and how the Fermi surface changes since it can be used to explain the unusual $\mathrm{H}_{c 2}$ curvature. The change in the Fermi surface in UCoGe motivated us to investigate in detail the Hall effect in this uranium compound. To date, among uranium based superconducting ferromagnets, detailed Hall effect measurements have been performed solely in $\mathrm{UGe}_{2}$ by Tran et al. [10].

In magnetic materials the Hall resistance is a sum of the normal and anomalous components,

$R_{\mathrm{Hall}} d=\rho_{x y}=R_{0} B_{z}+R_{A} M_{z}=\rho_{\mathrm{OHE}}+\rho_{\mathrm{AHE},}$

where $d$ is the sample thickness, $R_{0}$ and $R_{A}$ are coefficients that characterize the strength of the ordinary and anomalous Hall resistivity, respectively, $B_{\mathrm{z}}$ and $M_{\mathrm{z}}$ are the perpendicular components of the magnetic field and magnetization. The ordinary Hall effect (OHE) is related to the Lorentz force acting on moving charge carriers and is proportional to the magnetic field $B$. The anomalous Hall effect (AHE) is proportional to the $z$ component of the spontaneous magnetization $M$ and is determined by the spin-orbit interaction and the spin polarization of the carriers.

In this paper, we focus on the anomalous and ordinary Hall effect in UCoGe and discuss our results in the context of previous UCoGe single crystal magnetization and magnetoresistance studies. We report the low temperature measurements of the Hall effect in single crystal of UCoGe at $T=0.2 \mathrm{~K}$, i.e. in the region where both superconductivity and ferromagnetic order coexist. Both anomalous and ordinary Hall effects are separated from the total Hall effect and analyzed as a function of magnetic field direction $\theta$ from the easy magnetization axis ( $c$ axis) to the $a b$ plane ( $b$ being an intermediate hard magnetic axis, and $a$ the hardest magnetic axis in UCoGe). If the Hall effect is determined by the perpendicular components of the magnetic field and magnetization, a conventional $\cos \theta$ dependence is expected. However, we find that our results clearly deviate from this expectation and discuss the possi- ble sources to explain the unusual behavior of the Hall effect in UCoGe.

\section{EXPERIMENTAL METHOD}

The sample was grown at McMaster University from high-purity depleted Uranium (99.9\%), Co $(99.99 \%)$ and Ge $(99.999 \%)$ by Czochralski method in a tri-arc furnace under a continuous gettered $\mathrm{Ar}$ atmosphere. The as-grown rod was annealed in high vacuum for 14 days at $900{ }^{\circ} \mathrm{C}$ following Hardy and Huxley [11]. A characterization of the samples was performed by electrical resistivity measurements. The residual resistivity ratio $R(300 \mathrm{~K}) / R(1 \mathrm{~K})$ amounts to 5 and superconducting transition temperature $T_{\mathrm{sc}}$ is $0.4 \mathrm{~K}$. The $c$ axis crystal direction was determined from X-ray diffraction. The measurements were performed in a single-axis rotation probe in a dilution refrigerator and an $18 \mathrm{~T}$ superconducting magnet. Hall effect measurements were carried out with the current applied along the $c$ axis and voltage in the $a b$ plane (Figure 1). Magnetic field rotation was from the $c$ axis to the $a b$ plane. We should note that in our case the in-plane field orientation is unspecified, and involves a mixture of the $a$ and $b$ axis field effects.

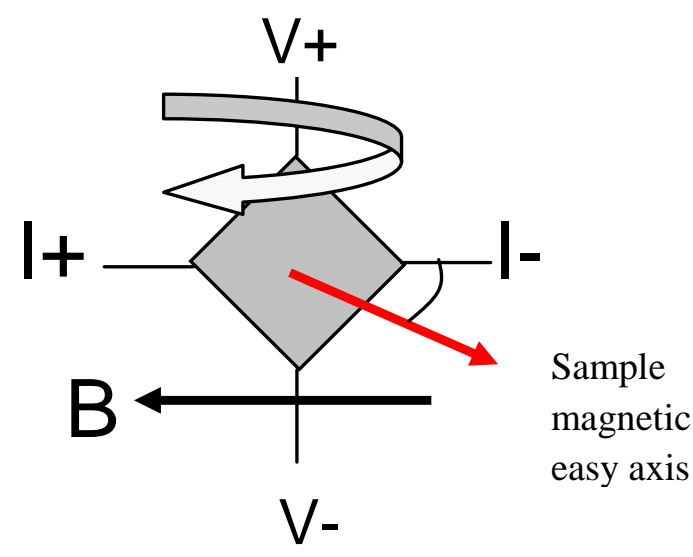

Figure 1. Lead wire configuration and experimental geometry for the Hall effect measurements in UCoGe as a function of the magnetic field direction

\section{RESULTS AND DISCUSSION}

A crucial issue in an experimental investigation of the anomalous Hall effect (AHE) is the separation between the AHE and the ordinary Hall effect (OHE), since both of them change as a function of the magnetic field. Below we present a detailed description of the separation of both the AHE and OHE from the total Hall effect in UCoGe and their evolution with magnetic field direction. 
Figure 2 shows the magnetic field dependence of the total Hall effect resistance, $R_{\text {Hall }}$, measured at $T=0.2 \mathrm{~K}$ up to $18 \mathrm{~T}$ and several field directions from the easy magnetization axis ( $c$ axis). The existence of two slopes, as well as rounding near the characteristic field (kink field $B_{\mathrm{k}}$ ) in the magnetic field dependence of total Hall effect, are evident at each field direction. The field-dependent slopes of $R_{\text {Hall }}$ versus $B$ and the change of sign at $B_{\mathrm{k}}$ are illustrated for $\theta=52^{\circ}$. The kink field is angle dependent and rounding of $R_{\text {Hall }}(B)$ near $B_{\mathrm{k}}$ becomes broader and less prominent at higher angles. The two slopes are related to AHE which dominates the change at fields below the kink field $B_{\mathrm{k}}$ and OHE which dominates the change at fields above the kink field. Below the kink field, $B \leq B_{\mathrm{k}}$, Hall resistance increases with the field, due to the variation of the magnetization (increasing with field) $[12,13]$, producing the large anomalous Hall effect. Near $B_{\mathrm{k}}$ there is rounding of $R_{\text {Hall }}(B)$ above which $\left(B>B_{\mathrm{k}}\right)$ the field dependence of the negative, ordinary Hall effect survives (the slope of $R_{\text {Hall }}$ $(B)$ decreases with increasing field).

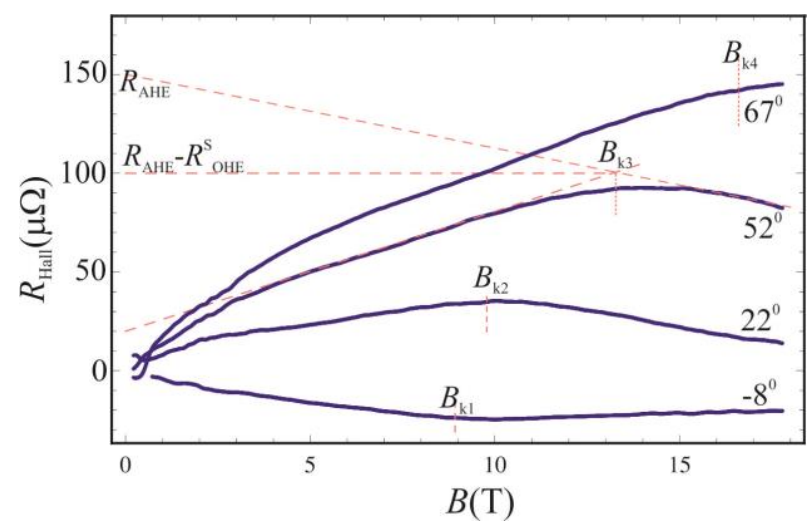

Figure 2. Magnetic field dependence of the total Hall resistance (blue curves) in UCoGe at $0.2 \mathrm{~K}$ for several field directions tilted from the easy magnetic axis ( $c$ axis) to the $a b$ plane. Red dashed lines indicate the kink fields $B_{\text {ki }}(i=1$,

$2,3,4)$ at different filed direction from the $c$ axis. The determination of the anomalous $R_{\mathrm{AHE}}$ and ordinary Hall resistance $R_{\mathrm{OHE}}$, at the kink field $B_{\mathrm{k} 3}$ for $\theta=52^{\circ}$, is indicated. We note that the extrapolation of the AHE at $\theta=67^{\circ}$ is estimated as the downturn in the $R_{\text {Hall }}(B)$ curve near $B_{\mathrm{k} 4}$ is not vivid for the fields up to $18 \mathrm{~T}$ indicating that the chang-

es in magnetization at this field direction occur at slightly higher kink field

Previously, the kink field anomaly was also reported for the field dependence of magnetoresistance in UCoGe at $T=90 \mathrm{mK}[8]$ and $T=40 \mathrm{mK}$ [12]. In order to discuss and compare our experimental results in the context of previous $\mathrm{UCoGe}$ studies, we have measured the magnetoresistance at
$T=0.2 \mathrm{~K}$ as shown in Figure 3. Here the change of field slope of magnetoresistance is seen as the magnetic field is rotated from negative to positive angels from the $c$ axis. In comparison with the previous results where the magnetoresistance scales (for angles $\theta \leq 60^{\circ}$ ) with the perpendicular component of the magnetic field $B \cos \theta$ in this case at $T=$ $0.2 \mathrm{~K}$, the scaling of magnetoresistance as well as of $R_{\text {Hall }}$ cannot be achieved.

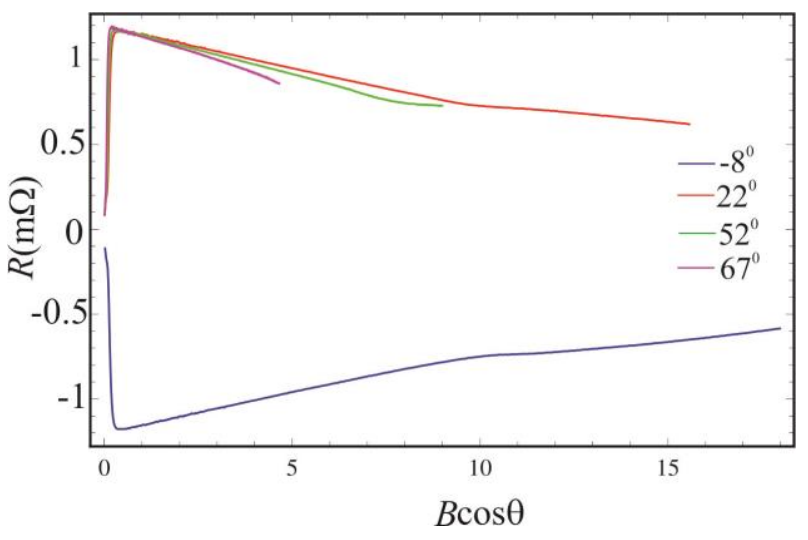

Figure 3. Scaling of the magnetoresistance in UCoGe with the perpendicular component of the magnetic field $B \cos \theta$ at $T=0.2 \mathrm{~K}$

The kink field anomaly in magnetoresistance in [12] as well as in the magnetic susceptibility of $\mathrm{UCoGe}$ is ascribed to the field induced magnetic transition, ferro-to-ferrimagnetic transition, due to the change in magnetic order which is in agreement with the polarized neutron diffraction experiments (PND) on UCoGe [14]. With high field magnetoresistance and Hall effect measurements at $T=0.2 \mathrm{~K}$ we find that the magnetic field induced moment polarization in UCoGe occurs even at higher temperature close to the superconducting transition temperature $\left(T_{\mathrm{sc}}=0.4 \mathrm{~K}\right)$. Consequently, the kink field $B_{\mathrm{k}}$ is the moment polarization field in UCoGe and the induced moment polarization is driven to higher $B_{\mathrm{k}}$ with the rotation from the $c$ axis. Recently, systematic magnetization and magnetoresistance measurements in UCoGe in high magnetic fields have shown that at low temperature a moment polarization in UCoGe in a field $B \| c$ of $23 \mathrm{~T}$ and $B \| b$ of $50 \mathrm{~T}$ leads to well defined anomalies in both magnetization and magnetoresistance [13] as also are observed here in magnetoresistance and Hall effect in fields up to $18 \mathrm{~T}$. All present studies show that the kink anomaly is a common feature in UCoGe since it is also present in the magnetoresistance and thermopower for $B \| b$. For UCoGe, the question is whether is $B_{\mathrm{k}}$ controlled by magnetic 
fluctuations or the Fermi surface effects. A possible source for the absence of scaling with $B \cos \theta$ of both the magnetoresistance and Hall effect is the angular dependent variation in the magnetization, both in its direction and its magnitude, due to the strong magnetic anisotropy in $\mathrm{UCoGe}$. To further address above issues we studied in detail the angular dependence of the two effects that contribute to $R_{\text {Hall: }}$ the $\mathrm{OHE}$ and $\mathrm{AHE}$.

To discuss the results, we employ the conventional, i.e., saturation value of the anomalous Hall resistance, $R_{\mathrm{AHE}}(\theta)$, and the ordinary Hall resistance at the characteristic field, $R_{\mathrm{OHE}}=R_{\mathrm{OHE}}^{\mathrm{S}}\left(B_{\mathrm{k}}\right.$, $\theta)$. In order to separate both effects and analyze how they change with magnetic field direction the AHE was extrapolated to zero field from the high field $R_{\text {Hall }}$ versus $B$ measurements up to $B=18 \mathrm{~T}$ at given angle (from $\theta=-8^{\circ}$ to $\theta=67^{\circ}$ ). The determination of both quantities from $R_{\text {Hall }}(B)$ below and above the kink field $B_{\mathrm{k}}$ is illustrated for $\theta=52^{\circ}$ in Figure 2.

The angular dependence of the two components that contribute to the Hall effect in UCoGe is shown in Figure 4. As expected from above discussion, the AHE has a dominant contribution to the total Hall effect as magnetic field is rotated from the $c$ axis to the $a b$ plane.

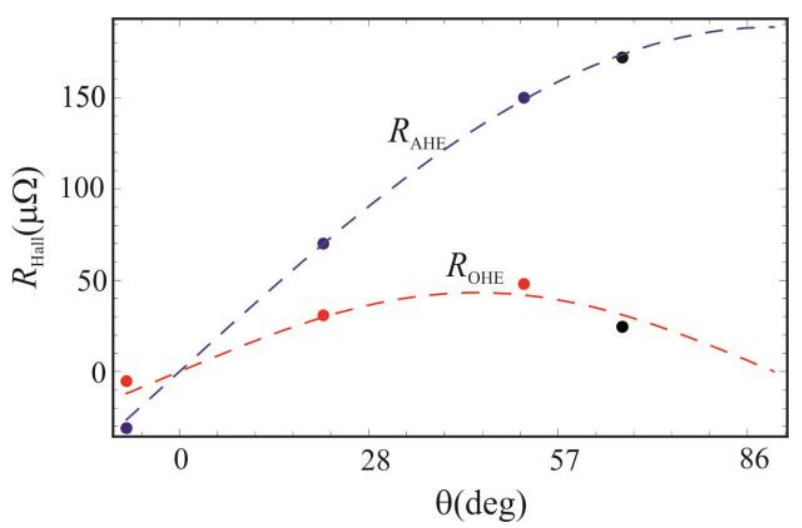

Figure 4. Angular dependence of the anomalous and ordinary Hall resistance, $R_{\mathrm{AHE}}$ (blue symbol) and $R_{\mathrm{OHE}}$ (red symbol). The point at $\theta=67^{\circ}$ as an estimated value is marked with a black symbol. Dashed lines (blue for the AHE and red for the OHE) are best fits to the both components. We note that both Hall effect components do not follow the $\cos \theta$ dependence

The data presented in Figure 4 clearly deviate from the conventional $\cos \theta$ dependence, whereas a good fit is found with

$$
R_{\mathrm{AHE}}(\theta)=a \sin \theta \quad \text { and } \quad R_{\mathrm{OHE}}(\theta)=b \sin 2 \theta
$$

for the following values of the parameters $a$ and $b$ :

$$
a=0.00018 \mu \Omega, b=0.000045 \mu \Omega .
$$

We note that the value of the AHE at $\theta=67^{\circ}$ is estimated as the field change of the $R_{\text {Hall }}(B)$ curve near the kink field $B_{\mathrm{k} 4}$ is not evident for the fields up to $18 \mathrm{~T}$ indicating that the changes in magnetization at this field direction occur at slightly higher kink field.

Commonly, the AHE is linked to the magnetization and is determined by the perpendicular component of spontaneous magnetization, $M_{z}$, but the present data show completely different behavior. According to the obtained $\sin \theta$ dependence it follows that the AHE is determined by the parallel component of the magnetization. To the best of our knowledge, in UCoGe, magnetization has not been measured yet as a function of the angle between the applied magnetic field and the easy magnetic axis. This does not allow us to make a comparison in order to determine if the AHE is affected by magnetization response or by other magnetic field effects. Nevertheless, in UCoGe, the observed large AHE contribution indicates that changes in the magnetization both in its direction and magnitude occur when magnetic field is rotated from the uniaxial magnetic axis ( $c$ axis) to the $a b$ plane. Recently, angle-resolved nuclear magnetic resonance (NMR) measurements in UCoGe have shown that the parallel component of the magnetic field $B \sin \theta$ is responsible for the longitudinal ferromagnetic fluctuations [15] which can drive the system towards the ferromagnetic instability. Indeed, ferromagnetic fluctuations which are due to the applied field can induce changes in the magnetization like the moment polarization (spin polarization as indicated by the PND experiments) reflected through the appearance of the slight rounding at the kink field (where magnetization saturates) and above the kink field there are no further changes in magnetization that can lead to second field induced moment polarization and consequently another anomaly is not expected to be observed in the AHE.

Not only the AHE is larger it also has a strong feedback on the angular dependence of the OHE. The OHE is not simply proportional to the perpendicular component of the magnetic field as expected implying that it is affected by the AHE and consequently by variation in both the direction and magnitude of the magnetization. These variations can eventually lead to decrease of the number of electron carriers in UCoGe as field is rotated towards the $a b$ plane on the account of increased 
number of hole carriers due to the predominant AHE contribution in the $a b$ plane.

Usually, the sign of the Hall coefficient prescribes the type of dominant charge carriers implying that the effects arising from the Fermi surface change in UCoGe must be taken into consideration. The change in the sign of total Hall effect for each field direction at the kink field $B_{\mathrm{k}}$ implies that at least two kinds of charge carries are present, i.e. suggests some Fermi surface reconstruction around this field which could be the result of a delocalization of some of the $5 f$ electrons. The opposite sign of the two contributions indicates that in UCoGe the anomalous Hall effect is of hole type and the ordinary Hall effect is produced by electron carriers.

Theoretically calculated de Haas van Alphen frequencies in the ferromagnetic state of UCoGe which come from a closed Fermi surface for a field rotation from the $c$ axis to $a b$ axis show that the largest frequency of $3.72 \mathrm{kT}$ at $\theta=0^{\circ}$ is obtained for this geometry and it slightly decreases in value with increasing angle to $\sim 2.7 \mathrm{kT}$ at $\theta=60^{\circ}$ [16]. The observed frequency decreases above $\theta=30^{\circ}$, accompanied with the currently observed OHE (which is linked to the type of carriers and their number) decrease at angles above $\theta=52^{\circ}$ suggest possible small shrinkage of the volume of the Fermi surface. However, a small misoriented crystal in the measured sample and the small misorientation for the field direction in the experiment could lead to different field direction at which the decrease in both de Haas van Alphen frequency and OHE is observed.

In conclusion, the present work shows that in UCoGe the Hall effect and the observed angle dependent kink field anomaly may be a manifestation of both the ferromagnetic fluctuations which lead to changes in the magnetization and the Fermi surface effects. However, which of these effects would contribute more to the observed field induced moment polarization (kink anomaly) in UCoGe and is still a question that should require consideration. This only confirms that in UCoGe very complex mechanisms drive the enigmatic behavior of this system.

Acknowledgement. We are grateful to M. Almeida, A. P. Gonçalves, M. S. Henriques, G. M. Luke and T. J. Williams for providing the UCoGe single crystals. The work was performed at the National High Magnetic Field Laboratory, supported by NSF Grant No. DMR0654118, by the State of Florida, and the DOE. Work by E.S. is supported by NSF-DMR 1005293 and 1309146.

\section{REFERENCES}

[1] S. S. Saxena, P. Agrwal, A. Ahilan, F. M. Grosche, R. K. W. Haselwimmer, M. J. Steiner, E. Pugh, I.
R. Walker, S. R. Julian, P. Monthoux, G. G. Lonzarich, A. Huxley, I. Sheiken, D. Braithwaite, J. Flouquet, Superconductivity on the border of itinerant-electron ferromagnetism in $\mathrm{UGe}_{2}$, Nature (London), 406 (2000), pp. 587-592.

[2] D. Aoki, A. Huxley, E. Ressouche, D. Braithwaite, J. Flouquet, J. P. Brison, L. Lhotel, C. Paulsen, Coexistence of superconductivity and ferromagnetism in URhGe, Nature (London), 413 (2001), pp. 613-616.

[3] N. T. Huy, A. Gasparini, D. E. de Nijs, Y. K. Huang, J. C. P. Klaasse, T. Gortenmulder, A. de Visser, A. Hamann, T. Görlach, H. v. Löhneysen, Superconductivity on the border of weak itinerant ferromagnetism in UCoGe, Phys. Rev. Lett., 99 (2007), 067006.

[4] A. de Visser, N. T. Huy, A. Gasparini, D. E. de Nijs, D. Andreica, C. Baines, A. Amato, Muon spin rotation and relaxation in the superconducting ferromagnet UCoGe, Phys. Rev. Lett., 102 (2009), 167003.

[5] T. Ohta, T. Hattori, K. Ishida, Y. Nakai, E. Osaki, K. Deguchi, N. K. Sato, and I. Satoh, Microscopic coexsistance of superconductivity and ferromagnetism in single-crystal UCoGe, J. Phys. Soc. Jpn., 79 (2010), 023707.

[6] N. T. Huy, D. E. de Nijs, Y. K. Huang, A. de Visser, Unusual upper critical field of the ferromagnetic superconductor UCoGe, Phys. Rev. Lett., 100 (2008), 077002.

[7] D. Aoki, T. D. Matsuda, V. Taufour, E. Hassinger, G. Knebel, J. Flouquet, Extremly large and anisotropic upper critical field and the ferromagnetic instability in UCoGe, J. Phys. Soc. Jpn., 78 (2009), 113709.

[8] D. Aoki, I. Sheikin, T. D. Matsuda, V. Taufour, G. Knebel, J. Flouquet, First observation of quantum oscillations in ferromagnetic superconductor UCoGe, J. Phys. Soc. Jpn., 80 (2011), 013705.

[9] L. Malone, L. Howald, A. Pourret, D. Aoki, V. Taufour, G. Knebel, J. Flouquet, Termoelectricity of the ferromagnetic superconductor UCoGe, Phys. Rev. B, 85 (2012), 024526.

[10] V. H. Tran, S. Paschen, R. Troć, M. Baenitz, F. Steglich, Hall effect in the ferromagnet $\mathrm{UGe}_{2}$, Phys. Rev. B, 69 (2004), 195314.

[11] F. Hardy, A. D. Huxley, $p$-Wave superconductivity in the ferromagnetic superconductor URhGe, Phys. Rev. Lett., 94 (2005), 247006.

[12] E. Steven, A. Kiswandhi, D. Krstovska, J. S. Brooks, M. Almeida, A. P. Gonçalves, M. S. Henriques, G. M. Luke, T. J. Williams, Robust properties of the superconducting ferromagnet UCoGe, Appl. Phys. Lett., 98 (2011), 132507.

[13] W. Knafo, T. D. Matsuda, D. Aoki, F. Hardy, G. W. Scheerer, G. Ballon, M. Nardone, A. Zitouni, C. Meingast, J. Flouquet, High-field moment po- 
larization in the ferromagnetic superconductor UCoGe, Phys. Rev. B, 86 (2012), 184416.

[14] K. Prokeš, A. de Visser, Y. K. Huang, B. Fåk, E. Ressouche, Anomalous spin distribution in the superconducting ferromagnet UCoGe studied by polarized neutron diffraction, Phys. Rev. B, 81 (2010), 180407(R).

[15] T. Hattori, Y. Ihara, Y. Nakai, K. Ishida, Y. Tada, S. Fujimoto, N. Kawakami, E. Osaki, K. Deguchi,
N. K. Sato, I. Satoh, Superconductivity induced by longitudinal ferromagnetic fluctuations in UCoGe, Phys. Rev. Lett., 108 (2012), 066403.

[16] M. Samsel-Czekała, S. Elgazzar, P. M. Oppeneer, E. Talik, W. Walerczyk, R. Troć, The electronic structure of UCoGe by $a b$ initio calculations and XPS experiment, J. Phys.: Condens. Matter, 22 (2010), 015503.

\title{
ИЗУЧУВАНЕ НА ХОЛОВИОТ ЕФЕКТ ВО СУПЕРСПРОВОДНИОТ ФЕРОМАГНЕТ UCOGe
}

\author{
Даница Крстовска ${ }^{1}$, Eden Steven ${ }^{2}$, Andhika Kiswandhi ${ }^{2}$, James S. Brooks ${ }^{2}$ \\ ${ }^{1}$ Институт за физика, Природно-математички факултет, Универзитет „Св. Кирил и Методиј“, \\ Скопје, Република Македонија \\ ${ }^{2}$ National High Magnetic Field Laboratory, Florida State University, \\ Tallahassee, FL 32310, U.S.A.
}

Во овој труд се покажува дека Холовиот ефект во единичен кристал од UCoGe се менува со аголот $\theta$ помеѓу надворешното магнетно поле и лесната магнетна оска во полиња до 18 Т и температура од $0.2 \mathrm{~K}$, односно во областа во којашто и двете состојби, суперспроводноста и феромагнетизмот, коегзистираат. Наместо да ја следат конвенционалната зависност на $\cos \theta$ од аголот, и двете компоненти што го сочинуваат вкупниот Холов ефект, аномалниот и обичниот, покажуваат сосема поинакво однесување од очекуваното со ротацијата на магнетното поле. Се покажува дека аномалниот Холов ефект е одреден со паралелната компонента на магнетизацијата, што означува дека промените што настануваат кај магнетизацијата поради ротацијата на магнетното поле играат важна улога во набљудуваното необично однесување. Од друга страна, обичниот Холов ефект не може да се опише со едноставната релација на пропорционалност со нормалната компонента на магнетното поле, што укажува на тоа дека и оваа компонента подлежи на промените на магнетизацијата што настануваат до одредена вредност на магнетното поле (карактеристично, или кинкполе). Поларизација на магнетниот момент индуцирана од надворешното магнетно поле се набљудува и во Холовиот ефект како и во зависноста на отпорот од магнетното поле. Холовиот ефект го менува знакот во карактеристичното поле, што е индикација за постоење мала но сепак можна реконструкција на Фермиевата површина. Мерењата на Холовиот ефект во UCoGe покажуваат дека во овој суперспроводен феромагнет повеќе механизми придонесуваат за појава на набљудуваната поларизација на магнетниот момент при одредена вредност на магнетното поле.

Клучни зборови: суперспроводност; феромагнетизам; ураниумски материјал; UCoGe; аномален Холов ефект; обичен Холов ефект; кинк-поле; индуцирана поларизација на магнетен момент; Фермиева површина 